\title{
Plastic fuel Extraction from Various Waste Plastics
}

\author{
A.Pakiya pradeep, S. Gowthaman
}

\begin{abstract}
The rapid growth of the world population which leads to increase demand of plastic in many sectors such as construction, medical, engineering applications, automotive, aerospace and many food industries for packing purpose. These rapid populations of plastic create some serious issues to the environment and living beings. The plastics are non-degradable and emit poisonous gases during burning. In recent years, many researches being conducted to resolve the disposal issues of waste plastics and trying to convert it into useful products. The plastic is a material consists of any wide range of synthetic or semi-synthetic organic compounds, which are long molecules built around chains of carbon and hydrogen atoms. The conversion of waste plastics to hydrocarbon (HC) fuel is an effective idea for disposing of waste plastics. It will be controlled plastic population and fulfill the needs of petroleum fuel in the future. As per the survey, the fossil fuels run out earlier in 2088 due to drastic growth of automobiles and high production cost. The waste plastic contains hydrocarbon with calorific value of 41 $47 M J$ and it is almost equal to the calorific value of fossil fuels. There are many methods being used to extract liquid HC fuel from waste plastics and it has been reviewed elaborately in this paper. It also reviews composition of various plastics like polyethylene terephthalate, high density polyethylene, low density polyethylene, polyvinyl chloride and polypropylene polystyrene and analyse their properties. In addition, it includes the selection of plastic and catalyst for extraction process, research gap in the existing extraction methods and the effect temperature and process timing on oil yield.
\end{abstract}

Keywords: Plastics, Composition, Oil Extraction Methods, Maximum Yield, Properties of Plastic oil.

\section{INTRODUCTION}

$T_{\text {he plastic is one of the major materials in human life }}$ because it's low cost, ease of manufacturing, veracity and imperviousness to water. The application of plastic in a wide variety of sectors such as the automotive, construction, electronics, healthcare and textiles [1]. Almost $67 \%$ of the plastic waste belonged to the HDPE/ LDPE, $10 \%$ to PP, and $8.66 \%$ to PET amongst others [2]. Most of the waste plastics are dumping or burning by solid municipality [3]. The dumping of plastic waste were affects solid quality of adjacent area through the condemnation of toxic substance

Revised Manuscript Received on December 5, 2019

* Correspondence Author

A. Pakiya pradeep, Department of Automobile Engineering, Kalasalingam Academy of Reasearch and Education, Krishnankoil, Srivilliputtur, Tamilnadu, India. Email: igneshpradeep@gmail.com

S. Gowthaman*, Department of Automobile Engineering, Kalasalingam Academy of Reasearch and Education, Krishnankoil, Srivilliputtur, Tamilnadu, India. Email: gowthammech@ hotmail.com

and he also found that the method of land filling is risk because of its non degradable material led to land pollution[4-5]. In other method of waste management in municipality is burning, which has lack of knowledge to utilized plastic waste as an energy conversion. Due to that effect of burning is to generate the thermal and air pollution too [6].

In that deep discussion of different method of waste handling and recycling methods are not properly consumed the energy. In other that increasing of fuel price is a reflection of the demand of fossil fuel. Due to that consuming of fossil fuel, the demand will be expected to increase $84 \%$ in 2030 . So there is a wide researcher are motivated to discover and developing the potential energy sources to meet the feature demand of fossil fuel. In few years before the researcher were found plastic oil is to be an alternative fuel which has higher calorific value (> $41 \mathrm{MJ}$ ) and proved that it can be directly used in diesel engine. The challenges of plastic waste management and deflation of fossil can simultaneously addressed the production of fuel from plastic waste. The recycling of plastic into feedstock also known as chemical recycling is encouraged all over the world [7].

The chemical recycling of plastic waste like pyrolysis, catalytic cracking and hydrocracking are gained good characteristics of fuels, when compared over the other process. Although chemical recycling of waste plastic is reliable and sustainable method to producing hydrocarbon [8]. The pyrolysis is one of the methods of chemical recycling to produce hydrocarbon range fuels. In this method the waste plastics are intensively heated with short duration in oxygen free atmosphere and convert the waste plastic from long chain polymer into smaller or less chain molecules. At the end of pyrolysis has produced three major products are liquid oil, gas and residue which are valuable for industry especially production and refineries. Pyrolysis liquid oil can be used in several applications such as furnace, boiler, turbine and diesel engine without any need of upgrading and treatment of fuel oil [10]. In generally the pyrolysis results in liquid oil has contains low octane value and higher residue at moderate temperature, thus an inefficient process of producing gasoline range fuels [12-13]. product of gases has minimum calorific value which can be used to compensate the overall energy requirement of the pyrolysis plant [11] The product gases of the pyrolysis process are not used as fuel, because its required for further refining or upgraded to useable fuel products $[14,15]$.Pyrolysis is flexible method, thus it can be controls process parameter easily to produce desire product yield based on the preferences. 
Many researchers are chosen pyrolysis method of extracting hydrocarbon fuel since the process produced high yield of liquid oil up to $80 \mathrm{wt} \%$ in moderate temperature around $500^{\circ}$ $\mathrm{C}[9]$.

The presence of catalysts is significantly lower the operating temperature and degradation time [16] and also saves the energy requirement [61]. As results indicated that more conversion rates are gained during catalyst pyrolysis with wide range of polymers has lower operating temperature than pyrolysis process [17-18]. While pyrolysis of waste plastics is produced broad range of hydrocarbons from range of $\mathrm{C}_{5}$ to $\mathrm{C}_{28}$ [19], but in the presents of catalyst are produced higher selectivity of products in the range gasoline fraction $\left(\mathrm{C}_{5}-\mathrm{C}_{12}\right)$ [46]. In that brief study the catalyst cracking of plastic oil has contain less olefins, more branched hydrocarbon and aromatic content [35-50]. In additionally the presents of catalyst with polyethylene during catalyst cracking under the similar temperature and degradation time, as results observed that increased the gases product yields [20-21].

The extraction process of pyrolysis and catalytic pyrolysis are produced unsaturated hydrocarbons, a higher amount of coke [24] and the product has larger molecular weight distribution [53]. The process of pyrolysis cracking in high pressure hydrogen atmosphere is named as hydrocracking, which has been convert the heavy or high boiling plastic molecules into lighter or low boiling molecules. Hydrocracking of plastic material has several merits compared to pyrolysis and catalytic pyrolysis as it is produced highly saturated liquid products [25]. The saturated liquid product can be directly used as transportation fuel or energy production. Insight of application of hydrocracking which is lowering the operating temperature, reducing the degradation time, reduced quantity of olefins, reduced the aromatic, and reduced the formation of coke. In additionally, the presence of high pressure hydrogen shows that in the removal of heteroatom's such as chlorine, bromine, and fluorine that could be exist in the waste plastic material [64]. Scherzer et al [22] and Weitkamp et al [23] have been studied the presents of hydrogen are simultaneously breaking the carbon bond $(\mathrm{C}-\mathrm{C})$ and successfully formed the unsaturated molecules during hydrogenation.

In several journals were published regarding the potential source of various types waste plastics in pyrolysis, catalytic pyrolysis and hydrocracking for liquid oil production. In several studies are noted that the product quantity of yield and quality are highly depend upon the operation parameters. The objective is to review the different types of plastic fuel oil extraction though the pyrolysis, catalyst pyrolysis and hydrocracking that have been explored together with the main affecting parameters, that should be needed to maximize liquid oil production and enhance the oil quality. The important parameters are degradation temperature, residence time, pressure, type of catalyst material used and their effect and fluidized gas its flow rate or its pressure. Due to the effective study of parameters which is useful for give appropriate recommendation for their use.

\section{TYPES AND COMPOSITION OF PLASTICS}

The various sorts of plastic have various organizations are accounted for in proximate investigation. In that proximate investigation can be estimated the compound properties of the plastic material dependent on four specific components there are dampness content, fixed carbon, unstable issue and slag content. The contaminant of unpredictable issue and fiery debris are the significant elements that can be an effective generation of fluid oil in pyrolysis extraction process [24]. The choices of high volatile matter plastic material to chemical recycling methods are leads to produce high yield of liquid oil while decreasing the ash content in the oil, consequently increased the gases yield and char formation [9].

The proximate analysis of different plastic materials is shown in table I. From the Table I, it was studied that the volatile matter of all plastic materials are very high due to ash content is considerably low. As the results of proximate analysis showed the material PVC PS and PET has no ash content present and the material PP has high ash present. More over the PET material and PVC has contains higher amount of fixed carbon. These properties were indicated the plastic materials have high amount of potential to gained large amount of liquid oil though the chemical recycling method. Since the basic study of proximate analysis are used for choice of material to process there after discussion about the process parameter were involved during the chemical recycling process that would have major effects in the liquid oil production.

Table: I Proximate analysis of plastics [65]

\begin{tabular}{|c|c|c|c|c|c|}
\hline $\begin{array}{l}\text { Type of } \\
\text { plastics }\end{array}$ & $\begin{array}{c}\text { Plastic } \\
\text { type } \\
\text { marks }\end{array}$ & $\begin{array}{c}\text { Moisture } \\
(w t \%)\end{array}$ & $\begin{array}{r}\text { Fixed } \\
\text { carbon } \\
(w t \%)\end{array}$ & $\begin{array}{c}\text { Volatile } \\
(w t \%)\end{array}$ & $\begin{array}{r}\text { Ash } \\
(\mathrm{wt} \%)\end{array}$ \\
\hline Polyethylene & & 0.46 & 7.77 & 91.75 & 0.02 \\
\hline Terephthalate & & 0.61 & 13.17 & 86.83 & 0.00 \\
\hline High-density & & 0.00 & 0.01 & 99.81 & 0.18 \\
\hline polyethylene & & 0.00 & 0.03 & 98.57 & 1.40 \\
\hline Polyvinyl & & 0.80 & 6.30 & 93.70 & 0.00 \\
\hline chloride & & 0.74 & 5.19 & 94.82 & 0.00 \\
\hline Low-density & & 0.30 & 0.00 & 99.70 & 0.00 \\
\hline polyethylene & & -- & -- & 99.60 & 0.40 \\
\hline Polynronvlene & & 0.15 & 1.22 & 95.08 & 3.55 \\
\hline Polypropylene & & 0.18 & 0.16 & $9 \%$ & 1.94 \\
\hline Polystyrene & & 0.25 & 0.12 & 99.63 & 0.00 \\
\hline & & 0.30 & 0.20 & 99.50 & 0.00 \\
\hline Polyethylene & & 0.10 & 0.04 & 98.87 & 0.99 \\
\hline $\begin{array}{l}\text { Acrylonitrile } \\
\text { butadiene }\end{array}$ & & 0.00 & 1.12 & 97.88 & 1.01 \\
\hline $\begin{array}{l}\text { Polyamide } \\
\text { (PA) or }\end{array}$ & & 0.00 & 0.69 & 99.78 & 0.00 \\
\hline $\begin{array}{l}\text { Polybutylene } \\
\text { terephthalate } \\
\text { ( PBT) }\end{array}$ & & 0.16 & 2.88 & 97.12 & 0.00 \\
\hline
\end{tabular}

\section{SELECTION OF PLASTIC MATERIAL}

The material selection is an important issue that can be used for oil extraction process. The production rate, fuel property, process capability and toxicity of oil are depended on plastic material and catalysts used in the process. Kumar et al [26] 
extracted $\mathrm{HC}$ fuel from various plastic wastes (HDPE, LDPE, PP, PS, PVC, PET, PA, PUR etc) by pyrolysis process. It was found that the materials like HDPE, LDPE, PP and PS were produced high quality HC fuel with better fuel properties. Polypropylene has required lower activation energy than that of polyethylene [39]

From the several practices, it has been concluded that the material of HDPE could be successfully degraded to gasoline and diesel fractionate hydrocarbon fuels in a suitable process conditions with different catalyst. Sing et al [27] conducted the pyrolysis process with HDPE virgin plastic waste with $5 \%$ wt of $\mathrm{COCO}_{3}$ catalyst in a borosil glass reactor at a temperature of $395^{\circ} \mathrm{C}$. It has been found that the above process extracted $92 \%$ and $91 \%$ liquid fuel obtained from virgin and waste HDPE plastics and also found that the virgin plastic are gained slightly more oil over the waste plastic. In addition, he found that the absent of impurities will help to increase the oil yield and more conversion of gases into liquid. William et al [28] extracted the fuel from refrigeration plastic waste (HIPS) by pyrolysis process and it produced $77.1 \%$ oil. This extracted HC oil contains fewer amounts of bromine and chlorine (0.96\%). Sarkar et al [29] used PETE-1 with $\mathrm{Ca}\left(\mathrm{OH}_{2}\right)$ catalyst in the catalytic cracking process at temperature of $405^{\circ} \mathrm{C}$. At end of the process, it was found that the extracted oil contains $14.25 \%$ of water with an effect of hydroxyls components which are present in the catalyst. A continuous liquid fraction distillation process can reduce the formation of light gas in yield and also found that the mixture of LDPE, HDPE, PS and PP yield $87.19 \%$ fuel with $20 \mathrm{wt} \%$ $\mathrm{ZnO}$ catalyst at $200-400^{\circ} \mathrm{C}$ in steel bench reactor (Hazrat et al 2015). It was found that the lowest yield of oil $2 \%$ for PVC compared with other materials like PE, PP, PS and PET. The mixed of these plastics with PVC also given lower yield of $48.2 \%$. From the catalytic cracking process, it was found that the PVC produced $38 \%$ gas and $52 \%$ of carbon residues. In another studied the regular pyrolysis reactor cannot be used for pyrolysed the PVC material due to the product of HCL acid highly corrosive with reactor material [scott et al] and the mixed plastic with PVC produced lower yield.

\section{SELECTION OF CATALYST USED IN PYROLYSIS PROCESS}

A wide verity of catalyst used in waste plastic pyrolysis process that has been set in either the pyrolysis reactor (in situ) or a free synergist bed (in-line). The selectivity of impetus is rely upon structure, acidity, reuse and regeneration. The destructive stimulus zeolites, HZSM-5, HY, H $\beta$ and HUSY are commonly used in pyrolysis process. These driving force are progresses the carbocationic part of pyrolysis volatiles, following reaction of isomerization, oligomerization-breaking, hydrogen trade and improved the de-bromine viability [47-49].

\section{V.PLASTIC FUEL EXTRACTION METHODS}

One of the most demanding research topics in the world is extraction of fuel from plastic waste. The different extraction processes are available to meet the fossil fuel demand like thermal cracking, hydro cracking, catalytic cracking, gasification and co-pyrolysis.

\section{A. Pyrolysis}

The pyrolysis extraction process is converting the large polymer into smaller hydrocarbons in the absence of oxygen free atmosphere at a temperature between 350 to $900{ }^{\circ} \mathrm{C} \mathrm{Scott}$ et al 1999. In this pyrolysis can be obtained in different proportions by the appropriate selection of plastic waste material, thermal cracking/ degradation temperature, choice of catalyst and degradation time [30].

Das et al [31] used LDPE, HDPE and PP waste plastic material for slow pyrolysis in a semi batch reactor at a temperature of $350-400^{\circ} \mathrm{C}$ in nitrogen atmosphere. The polypropylene and HDPE waste gives the highest oil yield $81.97 \%$ at process temperature $375^{\circ} \mathrm{C}$ and mixed waste give appropriate yield of $76.38 \%$ at $400^{\circ} \mathrm{C}$ process temperature. Miandad et al [32] were used PS, PP, PE,PET and mixed proportion of waste plastic material for pyrolysis process through the semi pilot scale reactor at temperature $450^{\circ} \mathrm{C}$ and 45 minutes of operation in organic gas atmosphere. Over several experiments done after concluded that the PS plastic waste is gave the maximum production of liquid oil (80.8\%) in comparison to other plastics.

Sharma et al [29] extracted waste plastic grocery bags through $2 \mathrm{~L}$ reactor at $420-440^{\circ} \mathrm{C}$ in $\mathrm{N}_{2}$ atmosphere were produced $74 \%$ of fuel oil. Khan et al 2016 extracting the fuel of HDPE material with pyrolysis process at temperature 330 $-490^{\circ} \mathrm{C}$ in self design stainless steel laboratory reactor produced $76 \%$ of oil yield. Hazrat et al [34] has experimented the pyrolysis with different plastic material and different composition in the steel bench top reactor in nitrogen atmosphere. As results shows that the PP and PE material gives maximum yield of $95 \%$ and $93 \%$, which the oil has higher heating value and heavy aromatic content. According to the fuel standards, the $\mathrm{HC}$ oil which was produced by pyrolysis process has many obstacles. Since the author conducted another experiment of liquefaction process for extracting fuel from the plastic waste with the present of $\mathrm{H}_{2}$ gas. The result shown that the liquefaction process extracted high quality $\mathrm{HC}$ fuel and also improved the production rate. Syamsirio et al [35] used plastic waste contains PE, HDPE and mixed (HDPE $+\mathrm{PE}$ ) to extracting fuel via pyrolysis process in a batch type reactor at $450^{\circ} \mathrm{C}$ in a nitrogen atmosphere. In this extraction process mixed plastic waste gives the maximum yield of oil $58 \%$, gas $10 \%$ and char $32 \%$.

Scott et al [36] has demonstrated that the sand fluidized bed minister was a proficient technique for decay of polyethylene to fluid item and it's produced most extreme yield of almost $90 \%$ of substantial oils at low temperature. At higher temperatures a lighter fluid item can be acquired with the yield of $30-45 \%$. William et al [28] conducted the experiment in fixed bed reactor at temperature of $600^{\circ} \mathrm{C}$ at the rate of $10^{\circ} \mathrm{C} / \mathrm{min}$ in $\mathrm{N}_{2}$ atmosphere and consequently the CRT waste plastic produced $83.9 \%$ of oil. The refrigeration plastic (HIPS) and mixed WEEE plastic have $76.5 \%$ and $70.6 \%$ oil. Alston et al [37] has demonstrated that the quick pyrolysis in the sand bed reactor to be a productive strategy for deterioration of polyethylene with most extreme yield of about $90 \%$ of substantial oils at least temperature. 


\section{Plastic fuel Extraction from Various Waste Plastics}

At higher temperature lighter fluid item can be acquired with yield of $30-45 \%$. Miskolczi et al [39] has been researched a pilot scale pyrolysis process with waste plastic waste decayed in a cylinder reactor temperature at $520^{\circ} \mathrm{C}$, utilizing hourly feed rate of $9 \mathrm{~kg}$. The transformation of waste plastic into gas and light oil portion with yield of $20-48 \%$ and $17-36 \%$ is relying on the utilized parameters.

The degradation time are varied when pyrolysis of waste electronic and electrical equipment due to the presence of metal components with this material required more temperature and degradation time when compared to plastic material like HDPE, PP etc. Shah et al [42] had done the pyrolysis process with LDPE and PP waste plastics in self designed reactor at various operating temperature from the range of $200-275^{\circ} \mathrm{C}$ with 80 minutes duration. During the experiment the author was noted that the variation of temperature and degradation time has increased the operating pressure, which is helpful for effective conversion of liquid HC oil. Kumar et al [43] has pyrolysis house hold waste plastic (HDPE, LDPE and PP) in the semi batch reactor at heated at a rate of $20^{\circ} \mathrm{C} / \mathrm{min}$ and subsequently held at the final temperature for $8 \mathrm{hr}$. The degradation of pyrolysis process at lower temperature and long duration supports the chain and random reaction which is leads to the produced lighter hydrocarbons. William et al [38] has pyrolysis of waste electrical and electronic equipment in fluid bed rector at the temperature of $600^{\circ} \mathrm{C}$ with heat rate of $10^{\circ} \mathrm{C} /$ minute. The higher temperature and long degradation time is useful for produced high amount liquid oil and minimize the halogen components present in liquid oil.

\section{B. Catalytic Pyrolysis}

The utilization of catalyst in catalytic pyrolysis process is positive to deliver limited items conveyance. Accordingly the procedure can be adjusted towards the generation of light olefins, gas or diesel. The choice of impetus is relying on the appropriate acridity and shape selectivity. What's more, the nearness of impetus may bring down the pyrolysis temperature and corruption time, which is especially high in the generation of aromatics and light olefins by pyrolysis process [40].

The presence of catalyst in pyrolysis of plastic waste is known as catalytic pyrolysis process and it has several advantages then regular pyrolysis process. The main advantages of catalytic pyrolysis are faster operation and a lower temperature which is significantly reduced the energy input. In additionally, the presence of zeolite catalyst during catalyst pyrolysis has produced high quality products in the range of automobile engine fuel, so that less needs to further treatment of fuel oil. In thermal pyrolysis product of oil is required further upgrading to use as engine fuel. The use of catalyst are lowers the requirement of pyrolysis temperature, minimize the operation time, produces gasoline and diesel fraction components [50]. Sing et al [27] has catalytic pyrolysis of waste and virgin HDPE material with catalyst cobalt corbonate $\left(\mathrm{CoCO}_{3}\right)$ in borosil glass reactor temperature of $20-395^{\circ} \mathrm{C}$ with duration of 4 Hour 20 minutes. In that results studied shows that the yield of liquid oil is about $80-92 \%$ for virgin HDPE and $79-91 \%$ for waste HDPE .
A little pilot scale reactor was charged to do the synergist pyrolysis of polystyrene (PS), polypropylene (PP), polyethylene (PE) and their blends in various proportions at $450^{\circ} \mathrm{C}$ and $75 \mathrm{~min}$. PS plastic waste brought about the most elevated fluid oil yield of 54\% utilizing common zeolite and half utilizing manufactured zeolite impetuses [45]. Sarkar et al [46] has Pyrolysed polyethylene (PETE-1) in an distillation unit at $405^{\circ} \mathrm{C}$ in an $\mathrm{CO}_{2}$ atmosphere Where $\mathrm{Ca}$ $(\mathrm{OH})_{2}$ catalysts is used. The product has minimum oil yield of $14.25 \%$ and contains $21.75 \%$ of water. As the test consequences of both GC/MS and DSC demonstrated that the Natural State Research (NSR PETE) fuel contains high unpredictable hydrocarbon mixes. FTIR additionally demonstrated that the useful gatherings of PETE fuel contain hydrocarbon and hydroxyl gathering. Vu et al [47] were discovered that the nearness of $\mathrm{HY}$ and $\mathrm{H} \beta$ zeolites has diminished the oil yield around $35 \mathrm{wt} \%$ with relating increment in wax and gas yields were gotten from warm corruption. HZSM-5 indicated less effect on item appropriation and delivered more oil contrasted and different zeolites. Mesoporous impetus of all-silica MCM- 41 acquired the most astounding oil yield of $67 \mathrm{wt} . \%$ and furthermore decreased the wax yield up to 8 wt. $\%$. The $\mathrm{Hy}$ and $\mathrm{H}-\beta$ catalyst were produce higher yield of aromatic wax (51\%), due to the size of microspores structure of catalyst and secondary reaction like hydrogen transfer, oligomerization, condensation and cyclization.

Hazrat et al [34] has found the mixture of LDPE, HDPE, PP and PS with catalyst $\mathrm{ZnO} 20 \%$ wt ratio in steel bench top reactor at temperature $200-400^{\circ} \mathrm{C}$ gives 87.18 $\%$ yield. During the process of catalytic pyrolysis a continuous liquid distillation process occurs and it can reduce the formation of gas in the liquid yield. Elrodi et al [44] used HZSM zeolite catalyst/ feed ratio of $2 / 1$ in catalytic pyrolysis process to produce the different fractions of total yields is about $99.6 \%$ achieved, at $450^{\circ} \mathrm{C}$ and $500^{\circ} \mathrm{C}$ operating condition. Sarkar et al [51] used catalyst $\mathrm{Ca}\left(\mathrm{OH}_{2}\right)$ with PETE waste material in catalytic pyrolysis process has to be mainly produce hydrocarbon and hydroxyl group of components. The fuel contains $86 \%$ of carbon and $13 \%$ hydrogen.

Syamsirio et al [35] has studied the present of catalyst to reduce the liquid fraction hydrocarbon. Result showed the use of natural zeolite gives the higher yield of liquid compared with y-zeolite. The higher surface area of catalyst occupies more gases and converts the lighter hydrocarbon as liquid oil. Moreover, it was found that the yield may reduce due to the presents of impurities and toxic components are mixed with plastic waste material. Miscolozki et al [39] used ZSM-5 catalyst with HDPE and PP in catalytic cracking at temperature $520^{\circ} \mathrm{C}$. The experimental results shown that the presence of catalyst for both feed stock has produced higher yield of liquid oil (> 80\%).

Sarkar et al [46] in thermal degradation of PETE-1 with Ca $\left(\mathrm{OH}_{2}\right)$ catalyst at temperature $400-530^{\circ} \mathrm{C}$ has produced higher volatile matter lower yield of liquid oil contain with water (oil1 $4.25 \%$ and $21.75 \%$ ). The reason of water content present on liquid oil is due to present of hydroxyl components in catalyst. 


\section{Catalytic hydrocracking}

The wide application of hydro raking in various industries, which has recovery of energy from the waste plastics in a hydrogen atmosphere in catalytic pyrolysis process. The presence of catalyst is in the form of heterogeneous mixture and acid based, which is supply the cracking properties. A main benefit of this hydrocraking of plastic waste is high gas product yield without char formation and avoids further treatment of liquid fuel. Ding et al [52] were discovered that fluid items are gotten from hydrocracking of HDPE over Ni/HSiAl and KC-2600 impetus has better nature of delivering business premium fuel, which has for the most part contains lighter hydrocarbons (C13) because of its contained more isoparaffins and less aromatics.

Aguado et al [53] was comparing the first and forth cycle hydrocraking of LDPE with Ni/h-Beta catalyst. Based on the results, it can be concluded that in regenerative $\mathrm{Ni} / \mathrm{h}$ - beta catalytic were good performed at fourth regenerative cycles, also keeping the overall yield of production, which indicates the higher acidity of catalyst. Escola et al 2011 [54] has demonstrates the most elevated selectivity of automotive fuels $(81 \%)$ was acquired in the presents of $\mathrm{Ni} 7 \% / \mathrm{h}$-Beta impetus. The nickel stacking is additionally improved olefins immersion up to Ni $7 \% /$ h- Beta. Also high cetane number lists (71-86) and octane numbers (89-91) were gotten over every one of the impetuses. As to various examination contemplated $\mathrm{Ni}$ substance, $\mathrm{Ni} 7 \%$ /h-Beta comprises a somewhat encouraging impetus for acquiring top notch energizes from LDPE pyrolysis oils. Serrano et al [56] has inferred that the crisp bimetallic $\mathrm{Ni}-\mathrm{Ru}$ impetuses marginally improved the light diesel to partake in the hydroreforming of the oils originating from LDPE warm splitting. All the different fraction of catalyst gives $<20 \%$ of heavy diesel fraction without any residue. From regenerated catalyst gives similar yield of light diesel fraction compared to fresh charge of catalyst.

khabib et al [57] had tentatively demonstrated that Sonochemically arranged Ni/ZA impetus had the option to expand the fuel division and furthermore contemplated the attributes of new, spent, and recovered $\mathrm{Ni} / \mathrm{ZA}$ impetus (catalyst) can be seen that the oxidation and decrease technique could build the sharpness of impetus. Expulsion of coke store just as the oxidation of mixes unequivocally adsorbed on the impetus surface may happen, bringing about the uncovered corrosive destinations of the impetus.

Fuentes et al [55] conduct an experiment of hydrocraking the PS material with various catalyst like pt/HZSM-5, $\mathrm{Pt} / \mathrm{h}-\mathrm{HZSM}-5, \mathrm{Pt} /$ ferrierite in tubular reactor at temperature $450^{\circ} \mathrm{C}$ in $\mathrm{H}_{2}$ gas flow with duration of 120 Minutes. As result indicated that $\mathrm{Pt} /$ Ferrierite has produced higher yield of naphthalene. Nonetheless, the better platinum scattering acquired in delaminated Pt/ITQ-6 contrasted with Pt/h-HZSM-6 makes the previous all the more intriguing for ulterior impetus enhancement.

Munir et al [8] has Used mixed plastic (HDPE, LDPE, PP and PS) to hydrocraking with two micro- mesoporous composite catalysts. The results indicated that the catalyst Al-SBA-15 and MZ16 are produced highest yield of oil 59\% and $54 \%$ at highest temperature of $425^{\circ} \mathrm{C}$. AL-SBA- 15 catalysts were showed better performance, chosen towards liquid formation and increasing hydrogen ability at very low temperature. In addition that the presence of catalyst and type of catalyst are generally not important at elevated temperatures. Farhat Ali et al [58] were found that the PS material with ZSM-5 catalyst produced higher yield of $91.5 \%$ of oil at $430^{\circ} \mathrm{C}$ temperature. whereas the results of mixed plastic material (HDPE, LDPE, PS and PP) with ZSM-5 catalyst gives the better results of $78.5 \%$ oil yield compared to other single material like HDPE,LDPE and PP. In addition, the PS and PP created a more prominent extent of materials bubbling beneath $550^{\circ} \mathrm{C}$ in the hexane solvent portion than both material LDPE and HDPE. Along these lines the co-preparing of plastics with resid demonstrated a critical improvement in the change rates showing that the response science of resid and plastics are entirely good.

Seo et al [59] were shown that the better yield of the transformation and item yields were exceedingly improved with impregnation of $\mathrm{Pt}$, suggesting that the hydrocracking of Pt/Al-SBA(X) advances through a bi- utilitarian component. Demonstrated the benefit of its mesoporous structure. The change of gas or potentially diesel-yields was improved by expanding the all out uncovered Pt surface region of impetus. Venkatesh et al [60] were indicated the effect of catalyst WZPt0.5 has minimum conversion with HDPE material and produce higher gasoline fraction liquid yield of $65.9 \%$ at $375^{\circ} \mathrm{C}$ temperature. At temperature $325^{\circ} \mathrm{C}$ hydrocraked the PP material with SZPt 0.5 catalysts were produced higher gasoline fraction of $71.7 \%$ yield.

Escolo et al. [63] found that the higher $\mathrm{Ni}$ loadings upgraded hydrocracking and hydrogenolysis exercises, expanding selectivity's towards lighter items and creating $2.9 \%$ methane over Ni 10\%/h-Beta. Nonetheless, over every one of these impetuses the real item was the gas portion, achieving a comparable selectivity (52-54\%). The most extreme consolidated selectivity to wanted items (gas + light diesel) was acquired over Ni 7\%/h-Beta (81\%). This impetus likewise demonstrated the most astounding hydrogenation movement, immersing over $95 \%$ of the olefins, and the most noteworthy measure of aromatics $(20.5 \%)$. Furthermore, the isoparaffins substance achieved a breaking point estimation of generally $40 \%$ above $7 \%$ of $\mathrm{Ni}$.

\section{COMPARISON OF PLASTIC OIL PROPERTIES WITH PETROLEUM FUELS}

The fundamental properties of the fuel are accounted for by Sharuddin et al [65]. It was demonstrated that the heat value of PS, PP, HDPE and LDPE are nearer to the business fuel, which is to be considered as high vitality use. Generally, the most minimal heat value of PET and PVC is about $<30 \mathrm{MJ} / \mathrm{kg}$ because of the nearness benzoic corrosive in PET and nearness of chlorine compound in PVC that will influence the nature of yield. Nearness of benzoic corrosive contains fragrant ring in PET as a reason of low calorific esteem. Along these lines the creator unmistakably delineated that the physical properties of plastics pyrolysis oil were near the properties of business gas and diesel. Accordingly, plastic pyrolysis oil has high potential to be utilized as elective vitality. 


\section{Plastic fuel Extraction from Various Waste Plastics}

\section{CONCLUSION}

In this reviewed that the different types of hydrocarbon extraction process of plastics materials and the effect of various extraction process like thermal cracking, catalytic cracking, hydrocraking and selecting their suitable catalyst and plastic material. The different extraction process mechanisms related to plastic degradation are discussed and the experimental works are compiled with database.

The pyrolysis is most economical, effective and flexible method of extracting hydrocarbon fuel. The temperature, pressure and degradation time can be easily varied to archive the desire product yield. In this pyrolysis studied the pressure of the process is no as well documented and temperature should not exceed the limit of $800^{\circ} \mathrm{C}$, but the process pressure can be considered as an excerpt of low temperature from 400 to $450^{\circ} \mathrm{C}$ gained higher yield.

The high qualities of hydrocarbon fuels are extracted through the catalytic cracking extraction process as the effective reaction of catalyst with plastics which leads to reducing the thermal energy input and degradation time.

Moreover, such a catalyst like zeolite (ZSM, HZSM), $\mathrm{CaCO}_{3}$, red mud and $\mathrm{ZnO}$ were produced high end quality of automotive fuels. In additionallythat the used of catalyst for has expensive process over the pyrolysis. The selection of catalyst is depending upon the poisoning and deactivation with the presents of feedstock. Our recommended that the catalyst/ feed ratio 1:10 as gained higher yield of oil.

In hydrocraking extraction process were improve the cracking through the high pressure hydrogen with catalyst, Which is helpful for increased the hydroxyl components present in the higher quality fractionate hydrocarbons. At temperature $400^{\circ} \mathrm{C}$ is recommended that for an efficient hydrocraking in the presents of catalyst. If the process at higher temperature produced most of the components are gaseous, where the initial hydrogen pressure is may be up to $20-60$ bar pressure. Increasing the degradation time will help to produce high quality of yield; an excess degradation time will convert the liquid component as a gases fraction component. A suitable catalyst with different temperature and pressure is recommended that the duration of degradation time is not more than 60 minutes.

One of the material selections is depend upon the availability and the major think that can be very useful for produced both higher quantity and quality of liquid oil yield without producing toxic components. It was observed that the many researcher selected plastic waste material are LDPE, HDPE,PET, PS and PP for extraction of hydrocarbon and the experimental results shows with the used those materials are gave the high quantity and quality of yield. However, few of the researchers found that the PVC produces hydrochloric acids during the process of extraction and also gives lower yield. Waste electrical and electronic plastic waste such as ABS and HIPS were produced halogen component. Addition of absorber had been avoided the formation of asides and halogen components in the liquid oil.

Over several studied it was concluded that the pyrolysis and catalytic of plastic waste is an economical method of fuel production. Otherwise, the operation parameter could be easily varied to predict the desire oil yield. The produced oil

has similar physical properties as compared to the commercial diesel and petrol. Thus the pyrolysis and catalytic pyrolysis process produced oil can be used as an alternative fuel without any further treatment.

\section{REFERENCES.}

1. R.R. N Sailaja Bhattacharya, Kaushik Chandrasekhar, M V Deepthi, Pratik Roy, and Ameen Khan (2018) "CHALLENGES AND OPPORTUNITIES Plastic Waste Management in India"

2. 'Indian Plastic Industry Set to Buck the Global Trend, Set to Grow $12 \%$ This Year'; refer to

https://www.indiainfoline.com/article/newstop-story/indian-plasticsindustry-set-to-buck-the-global-trend-set-togrow-12-this-year116091200141_1.html; last accessed on May 30, 2018.

3. M. Sharholy, K. Ahmad, G. Mahmood, and R.C. Trivedi (2008) "Municipal Waste Management in Indian Cities: A Review". Science Direct Waste Management 28: 459-67; refer to https:// www.unc.edu/courses/2009spring/envr/890/002/readings/ Solid Waste India Review 2008.pdf; last accessed on May 29, 2018.

4. V. Koushal, R. Sharma, M. Sharma, R. Sharma, V. Sharma (2014) "Plastics: Issues Challenges and Remediation" Int J Waste Resources 4: 134.

5. M.R. Gregory (2009) "Environmental Implications of Plastic Debris in Marine Settings: Entanglement, Ingestion, Smothering, Hangers-on Hitch-hiking and Alien Invasions" Philosophical Transactions of the Royal Society B: Biological Sciences, 364: 2013-25.

6. Floyo hasselriis, Gershman, Brickner and Bratton (2007) "Effects of Burning Municipal Waste on Environment and Health" Inc. Washington, DC, 2007 86-JPGC-EC-17.

7. P.K. Ramdoss, A.R. Tarrer (1998) "High-temperature liquefaction of waste plastics" Fuel 77 (1998) 293-299

8. Dureem Munir, Abdullaha, Frank Piepenbreier and Muhammad R. Usman (2017) "Hydrocracking of a plastic mixture over various micromesoporous composite zeolites" http://dx.doi.org/10.1016/j.powtec.2017.01.037

9. S.M. Fakhrhoseini, M. Dastanian (2013) "Predicting pyrolysis products of PE, PP, and PET using NRTL activity coefficient model" Hindawi Publishing Corporation; 2013. p. 1-5.

10. A.V. Bridgwater (2012) "Review of fast pyrolysis of biomass and product upgrading" Biomass Bioenergy 2012;38:68-94.

11. F. Abnisa, W.M.A. Wan Daud "A review on co-pyrolysis of biomass: an optional technique to obtain a high-grade pyrolysis oil. Energy Convers Manage 2014;87:71-85.

12. S.S. Kim, S. Kim (2004) "Pyrolysis characteristics of polystyrene and polypropylene in a stirred batch reactor" Chemical Engineering Journal 2004;98(1-2):53-60.

13. D. Seth, A. Sarkar (2004) "Thermal pyrolysis of polypropylene: effect of reflux-condenser on the molecular weight distribution of products" Chemical Engineering Science 2004;59(12):2433-45.

14. P. Onu, C. Vasile, S. Ciocı^lteu, S. Iojoiu, H. Darie (1999) "Thermal and catalytic decomposition of polyethylene and polypropylene" Journal of Analytical and Applied Pyrolysis 1999;49 (1-2):145-53.

15. H.S. Joo, J.A. Guin (1998) "Continuous upgrading of a plastics pyrolysis liquid to an environmentally favorable gasoline range product" Fuel Processing Technology1998;57:25-40

16. Ohkita H, Nishiyama R, Tochihara Y, Mizushima T, Kakuta N, Morioka Y. Acid properties of silica-alumina catalysts and catalytic degradation of polyethylene. Industrial \& Engineering Chemistry Research 1993;32(12):3112-6.

17. W.B. Ding, J. Liang, L.L. Anderson (1997) "Thermal and catalytic degradation of high density polyethylene and commingled post-consumer plastic waste" Fuel Processing Technology 1997;51(1-2):47-62.

18. S.Y. Lee (2001) "Catalytic degradation of polystyrene over natural clinoptilolite zeolite" Polymer Degradation and Stability 2001;74(2):297-305. 
19. W.C. McCaffrey, M.R. Kamal, D.G. Cooper (1995) "Thermolysis of polyethylene" Polymer Degradation and Stability 1995;47(1):133-9.

20. D.W. Park, E.Y. Hwang, J.R. Kim, J.K. Choi, Y.A. Kim, H.C. Woo (1999) "Catalytic degradation of polyethylene over solid acid catalysts" Polymer Degradation and Stability1999;65(2):193-8.

21. P.L. Beltrame, P. Carniti , G. Audisio, F. Bertini (1989) "Catalytic degradation of polymers: Part II. Degradation of polyethylene" Polymer Degradation and Stability1989;26(3):209-15.

22. J. Scherzer, A.J. Gruia (1996) "Hydrocracking science and technology." New York: Marcel- Dekker Inc.; 1996.

23. J. Weitkamp (2012) "Catalytic hydrocracking: mechanisms and versatility of the process" ChemCatChem 2012;4:292-6.

24. K.R. Venkatesh, J. Hu, J.W. Tierney, I. Wender "Hydrocracking of polyolefins to liquid fuels over strong solid acid catalysts" Fuel Chem 1995;40:788

25. J. Mosio-Mosiewski, M. Warzala, I. Morawski, T. Dobrzanski (1996) "High- pressure catalytic and thermal cracking of polyethylene" Fue Process Technol 2007;88. [359-4]. Process Technol 1996;49. [119-6].

26. Sachin Kumar, Achyut K. Panda and R.K. Singh (2011) "A review on tertiary recycling of high-density polyethylene to fuel. Resources" Conservation and Recycling 55 (2011) 893-910

27. M.V. Singh (2018) "Waste and Virgin high-density poly(ethylene) into Renewable Hydrocarbons Fuel by pyrolysis- catalytic cracking with a CoCO3 Catalyst" Journal of Analytical and Applied Pyrolysis, https://doi.org/10.1016/j.jaap.2018.06.003

28. William J. Hall, Paul T. Williams (2006) "Analysis of products from the pyrolysis of plastics recovered from the commercial scale recycling of waste electrical and electronic equipment" J. Anal. Appl.Pyrolysis 79 (2007) $375-386$

29. Brajendra K. Sharma, Bryan R. Moser, Karl E. Vermillion, Kenneth M. Doll and Nandakishore Rajagopalan, (2014) "Production characterization and fuel properties of alternative diesel fuel from pyrolysis of waste plastic grocery bag, Fuel Processing Technology 122 (2014) 79-90.

30. Achyut K Panda and R K Sing (2011) "Catalytic performances of kaoline and silica alumina in the thermal degradation of polypropylene" J Fuel Chem Technol, 2011, 39(3), 198-202

31. Pallab Das, Pankaj Tiwari (2018) "Valorization of packaging plastic waste by slow pyrolysis" Resources, Conservation \& Recycling 128 (2018) 69-77

32. R. Miandad, M.A. Barakat, Asad S. Aburiazaiza, M. Rehan, I.M.I. Ismail, A.S. Nizami (2016) "Effect of plastic waste types on pyrolysis liquid oil" http://dx.doi.org/10.1016/j.ibiod.2016.09.017

33. N. Miskolczi, A. Angyal , L. Bartha and I. Valkai, (2009) "Fuels by pyrolysis of waste plastics from agricultural and packaging sectors in a pilot scale reactor" Fuel Processing Technology 90 (2009) 1032 1040

34. M.A. Hazarat, M.G. Rasul and M.M.K. Khan, (2014) "A study on thermo- Chemical degradation for production of clean transport fuel and reducing plastic waste" Procedia Engineering 105 ( 2015) 865 876

35. Mochamad Syamsiro, Harwin Saptoadi, Tinton Norsujianto, Putri Noviasria,Shuo Chenga, Zainal Alimuddinc, Kunio Yoshikawaa (2014) "Fuel Oil Production from Municipal Plastic Wastes in Sequential Pyrolysis and Catalytic Reforming Reactors" Energy Procedia 47 (2014) 180 - 188

36. D. S. Scott,S. R. Czernik, J. Piskorz, and D. St. A. G. Radlein (1990) "Fast Pyrolysis of Plastic Waste" Energy \& Fuels 1990, 4, 407-411

37. Sue M. Alston,, Allan D. Clark, J. Cris Arnold, and Bridget K. Stein (2011) "Environmental Impact of Pyrolysis of Mixed WEEE Plastics Part 1: Experimental Pyrolysis Data” Environ. Sci. Technol. 2011, 45, 9380-9385

38. Chuan Ma, Jie Yu, Ben Wang, Zijian Song, Jun Xiang, Song Hu, Sheng Su,and Lushi Sun (2016) "Catalytic pyrolysis of flame retarded high impact polystyrene over various solid acid catalysts" http://dx.doi.org/10.1016/j.fuproc.2016.01.018

39. N. Miskolczi, A. Angyal , L. Bartha and I. Valkai (2009) "Fuels by pyrolysis of waste plastics from agricultural and packaging sectors in a pilot scale reactor" Fuel Processing Technology 90 (2009) 10321040

40. Gartzen Lopez, Maite Artetxe, Maider Amutio, Jon Alvarez, Javier Bilbao and Martin Olazar (2017) "Recent advances in the gasification of waste plastics. A critical overview" Renewable and Sustainable
Energy Reviews 82 (2018) 576-596

41. M.R.H. Khan, M.Sultan, M.R.almamun and M.R.Hasan (2016) "Pyrolytic weaste plastic oil and its Diesel blend : Fuel characterization" Jornal of environmental and public health volume 2016, article ID: 7869080

42. Sajid Hussain Shah, Zahid Mahmood Khan, Iftikhar Ahmad Raja, Qaisar Mahmooda, Zulfiqar Ahmad Bhatti, Jamil Khan, Ather Farooq, Naim Rashid and Donglei Wu (2010) "Low temperature conversion of plastic waste into light hydrocarbons" Journal of Hazardous Materials 179 (2010) 15-20

43. Sachin Kumar and R. K. Singh, (2011) "RECOVERY OF HYDROCARBON LIQUID FROMWASTE HIGH DENSITY POLYETHYLENE BY THERMAL PYROLYSIS" Brazilian Journal of Chemical Engineering,Vol. 28, No. 04, pp. 659 -667

44. Gorka Elordi, Gartzen Lopez, Roberto Aguado Martin Olazar and Javier Bilbao (2007) "Catalytic Pyrolysis of High Density Polyethylene on a HZSM-5 Zeolite Catalyst in a Conical Spouted Bed Reactor" https://www.researchgate.net/publication/230821399

45. R. Miandad, M.A. Barakat, M. Rehan, A.S. Aburiazaiza, I.M.I. Ismail , A.S. Nizami, (2017) "Plastic waste to liquid oil through catalytic pyrolysis using natural and synthetic zeolite catalysts" Waste Management 69 (2017) 66-78

46. Moinuddin Sarker, Aminul Kabir, Mohammad Mamunor Rashid, Mohammed Molla, and A. S. M. Din Mohammad (2011) "Waste Polyethylene Terephthalate (PETE-1) Conversion into Liquid Fuel" Journal of Fundamentals of Renewable Energy and Applications Vol. 1 (2011), Article ID R101202, 5 pages, doi:10.4303/jfrea/R101202

47. X.H. Vu, R. Eckelt, U. Armbruster, A. Martin (2014) "High-temperature synthesis of ordered mesoporous aluminosilicates from ZSM-5 nanoseeds with improved acidic properties" Nanomaterials 4 (2014) 712-725

48. Chuan Ma, JieYu, BenWang, ZijianSong, JunXiang, SongHu, Sheng $\mathrm{Su}$ and Lushi Sun (2016) "Chemical recycling of brominated flame retarded plastics frome-waste for clean fuels production :A review" Renewable and Sustainable EnergyReviews 61(2016)433-450

49. M. Boronat, A. Corma (2008) "Are carbenium and carbonium ions reaction intermediates in zeolite-catalyzed reactions" Appl Catal A 2008;336:2-10.

50. S.M. Al-Salem, A. Antelava , A. Constantinou, G. Manos and A Dutta (2017) "A review on thermal and catalytic pyrolysis of plastic solid waste (PSW)" Journal of Environmental Management 197 (2017) $177 \mathrm{e} 198$

51. Moinuddin Sarker, Aminul Kabir, Mohammad Mamunor Rashid, Mohammed Molla, and A. S. M. Din Mohammad (2011) "Waste Polyethylene Terephthalate (PETE-1) Conversion into Liquid Fuel" Journal of Fundamentals of Renewable Energy and Applications Vol. 1 (2011), Article ID R101202.

52. Weibing Ding, Jing Liang, and Larry L. Anderson (1997) "Hydrocracking and Hydroisomerization of High-Density Polyethylene and Waste Plastic over Zeolite and Silica-AluminaSupported Ni and Ni-Mo Sulfides" Energy \& Fuels 1997, 11, 1219 1224

53. J. Aguado, D. P. Serrano and J. M. Escola (2018) "Fuels from Waste Plastics by Thermal and Catalytic Processes: A Review" Ind. Eng. Chem. Res. 2008, 47, 7982-7992

54. J.M. Escola, J. Aguado, D.P. Serranoa, A. Garciaa, A. Perala, L. Brionesa, R. Calvoc and E. Fernandezc (2011) "Catalytic hydroreforming of the polyethylene thermal cracking oil over $\mathrm{Ni}$ supported hierarchical zeolites and mesostructured aluminosilicates" Applied Catalysis B: Environmental 106 (2011) 405-415

55. E.G. Fuentes-Ordonez, J.A. Salbidegoitia, J.L. Ayastuy, M.A. Gutiérrez-Ortiz,M.P. González-Marcos, J.R. González-Velasco (2013) "High external surface Pt/zeolite catalysts for improving polystyrenehydrocracking" Catalysis Today 227 (2014) $163-170$

56. D.P. Serrano, J.M. Escola, L. Briones, S. Medina and A Martinez.., (2015) "Hydroreforming of the oils from LDPE thermal cracking over $\mathrm{Ni}-\mathrm{Ru}$ and Ru supported over hierarchical Beta zeolite" Fuel 144 (2015) 287-294

57. Imam Khabib, Sri Kadarwati, and Sri Wahyuni (2014) "DEACTIVATION AND REGENERATION OF Ni/ZA CATALYST IN HYDROCRACKING OF POLYPROPYLENE" Indo. J. Chem., 2014, 14 (2), $192-198$ 
58. Mohammad Farhat Ali ,Mohammad Nahid Siddiqui and S. Halim Hamid Redhwi (2004) "Study on the conversion of waste plastics/petroleum resid mixtures to transportation fuels" J Mater Cycles Waste Manag (2004) 6:27-34 @ Springer-Verlag 2004 DOI 10.1007/s10163-003-0102-X

59. Myung-gi Seo, Dae-Won Lee, Kwan-Young Lee, Dong Ju Moon (2015) "Pt/Al-SBA-15 catalysts for hydrocracking of C21-C34 n-paraffin mixture into gasoline and diesel fractions" Fuel 143 (2015) 63- 71

60. K. R. Venkatesh, J. Hu, W. Wang, G. D. Holder, J. W. Tierney, and I. Wender (1996) "Hydrocracking and Hydroisomerization of Long- Chain Alkanes and Polyolefins over Metal-Promoted Anion-Modified Zirconium Oxides" Energy \& Fuels 1996, 10, 1163-1170

61. W.B. Ding, J. Liang, L.L. Anderson (1997) "Thermal and catalytic degradation of high density polyethylene and commingled post-consumer plastic waste" Fuel Processing Technology 1997;51(1-2):47-62.

62. J. Aguado, D.P. Serrano, J.M. Escola, and L. Briones (2013) "Deactivation and regeneration of a $\mathrm{Ni}$ supported hierarchical Beta zeolite catalyst used in the hydroreforming of the oil produced by LDPE thermal cracking" http://dx.doi.org/10.1016/j.fuel.2013.03.011

63. J.M. Escola, J. Aguado, D.P. Serrano and L. Briones (2014) "Transportation fuel production by combination of LDPE thermal cracking and catalytic hydroreforming" http://dx.doi.org/10.1016/j.wasman.2014.06.010

64. Dureem Munir, Muhammad F. Irfan, Muhammad R. Usman (2018) "Hydrocracking of virgin and waste plastics: A detailed review" Renewable and Sustainable Energy Reviews 90 (2018) 490-515

65. Shafferina Dayana Anuar Sharuddin, Faisal Abnisa, Wan Mohd Ashri Wan Daud, Mohamed Kheireddine Aroua (2016) “A review on pyrolysis of plastic wastes" Energy Conversion and Management 115 (2016)308-326

\section{AUTHORS PROFILE}

A.Pakiya pradeep, M.E., (Ph.D)., Published 1 paper

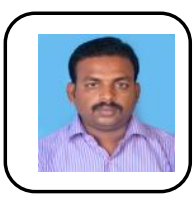

Dr. S Gowthaman, Ph.D., (IC engines), Published 11 papers in international publications, and membership in ISTE,. 